\title{
Predictors for reoperation after lower limb amputation in patients with peripheral arterial disease
}

\author{
Berli, Martin C ; Wanivenhaus, Florian ; Kabelitz, Method ; Götschi, Tobias ; Böni, Thomas ; Rancic,
} Zoran ; Waibel, Felix W A

\begin{abstract}
Major amputations in patients with peripheral arterial disease (PAD) carry a high risk for complications, including revision of the amputation, sometimes to a higher level. Determining a safe level for amputation with good wound healing potential depends largely on vascular measurements. This study evaluated potential predictive factors for revision of major lower extremity amputations in patients with PAD. A retrospective chart review of all major lower extremity amputations at our institution was conducted. Amputations due to trauma or tumor and below-ankle amputations were excluded. Patient demographics, level/type of amputation, level/time of revision, comorbidities and risk factors were extracted. 180 patients with PAD, mean age 66.48 (range: 31-93) years, 125 (69.4\%) male were included. Most $(154 / 180,86.6 \%)$ underwent below-knee amputation. $71(39.4 \%)$ patients had coronary arterial disease, $104(57.8 \%)$ had diabetes. More than half of patients, $(93 / 138 ; 51.7 \%)$ had undergone previous balloon angioplasty. $44(30 \%)$ patients required revision surgery: $42 / 180(23.3 \%)$ were revised at the same level, and in $12 / 180(6.7 \%)$ a more proximal amputation was necessary. PAD stage was not associated with the level of reamputation $(\mathrm{p}=0.4369)$. Significantly more patients who had previous balloon angioplasty required revision surgery $(66.7 \%$ versus $45.2 \%, \mathrm{p}=0.009) .67(37.2 \%)$ patients underwent preoperative TcPO2 measurement: $40 / 67$ (59.7\%) had TcPO2 $40 \mathrm{mmHg} ; 4 / 67(6 \%)$ had TcPO2 < $10 \mathrm{mmHG}$. Three patients with TcPO2 $40 \mathrm{mmHg}$, one with $30 \mathrm{mmHg}$ TcPO2 $40 \mathrm{mmHg}$ and one with $10 \mathrm{mmHg}$ TcPO2 $20 \mathrm{mmHg}$ required re-amputation to a more proximal level. TcPO2 measurements are useful for determining level of lower limb amputation and predicting wound healing problems when an amputation level with TcPO2 $<40 \mathrm{mmHg}$ is chosen. In transtibial amputations, TcPO2 $40 \mathrm{mmHg}$ does not safely predict wound healing.
\end{abstract}

DOI: https://doi.org/10.1024/0301-1526/a000796

Posted at the Zurich Open Repository and Archive, University of Zurich

ZORA URL: https://doi.org/10.5167/uzh-170735

Journal Article

Published Version

Originally published at:

Berli, Martin C; Wanivenhaus, Florian; Kabelitz, Method; Götschi, Tobias; Böni, Thomas; Rancic, Zoran; Waibel, Felix W A (2019). Predictors for reoperation after lower limb amputation in patients with peripheral arterial disease. Vasa, 48:419-424.

DOI: https://doi.org/10.1024/0301-1526/a000796 


\title{
Predictors for reoperation after lower limb amputation in patients with peripheral arterial disease
}

\author{
Martin C. Berli ${ }^{1}$, Florian Wanivenhaus ${ }^{1}$, Method Kabelitz ${ }^{1}$, Tobias Götschi ${ }^{2}$, \\ Thomas Böni ${ }^{1}$, Zoran Rancic ${ }^{3}$, and Felix W. A. Waibel ${ }^{1}$ \\ Department of Orthopaedic Surgery, Balgrist University Hospital, Zurich, Switzerland \\ ${ }^{2}$ Department of Orthopaedic Surgery, University of Zurich, Institute for Biomechanics, ETH Zurich, Balgrist Campus, Zurich, Switzerland \\ ${ }^{3}$ Division of Vascular Surgery, University Hospital Zurich, Zurich, Switzerland
}

\begin{abstract}
Summary: Background: Major amputations in patients with peripheral arterial disease (PAD) carry a high risk for complications, including revision of the amputation, sometimes to a higher level. Determining a safe level for amputation with good wound healing potential depends largely on vascular measurements. This study evaluated potential predictive factors for revision of major lower extremity amputations in patients with PAD. Patients and methods: A retrospective chart review of all major lower extremity amputations at our institution was conducted. Amputations due to trauma or tumor and below-ankle amputations were excluded. Patient demographics, level/type of amputation, level/time of revision, comorbidities and risk factors were extracted. Results: 180 patients with PAD, mean age 66.48 (range: 31-93) years, 125 (69.4\%) male were included. Most (154/180, 86.6\%) underwent below-knee amputation. 71 (39.4\%) patients had coronary arterial disease, 104 (57.8\%) had diabetes. More than half of patients, (93/138; 51.7\%) had undergone previous balloon angioplasty. 44 (30\%) patients required revision surgery: 42/180 (23.3\%) were revised at the same level, and in 12/180 (6.7\%) a more proximal amputation was necessary. PAD stage was not associated with the level of reamputation $(p=0.4369)$. Significantly more patients who had previous balloon angioplasty required revision surgery (66.7\% versus $45.2 \%, p=0.009) .67$ (37.2\%) patients underwent preoperative TcPO2 measurement: 40/67 (59.7\%) had TcPO2 $\geq 40$ mmHg; 4/67 (6\%) had TcPO2<10 mmHG. Three patients with TCPO2 $\geq 40 \mathrm{mmHg}$, one with $30 \mathrm{mmHg} \leq \mathrm{TCPO} 2 \leq 40 \mathrm{mmHg}$ and one with $10 \mathrm{mmHg} \leq \mathrm{TcPO} 2 \leq 20 \mathrm{mmHg}$ required re-amputation to a more proximal level. Conclusions: TcPO2 measurements are useful for determining level of lower limb amputation and predicting wound healing problems when an amputation level with TcPO2 $<40 \mathrm{mmHg}$ is chosen. In transtibial amputations, TCPO2 $\geq 40 \mathrm{mmHg}$ does not safely predict wound healing.
\end{abstract}

Keywords: Amputation, revision, level of amputation, peripheral arterial disease, TcPO2, diabetes mellitus

\section{Introduction}

In patients with advanced peripheral arterial disease (PAD), amputation is often the last option for treatment of uncontrollable pain or infection. Major amputations in vascular compromised patients carry a high risk for complications, including revision of the amputation, sometimes to a higher level. Across 12 studies, the mean revision rate of 3,454 lower limb amputations was $16.3 \%$ (range: $13.4 \%$ to $56 \%$ ) [1-12], with a mean rate of below-knee conversion to a higher level of amputation of $12.9 \%$ (range: $0 \%$ to $24 \%)$.

The healing potential of the amputation wound is severely limited in patients with PAD, due to the reduced perfusion of the area. The healing potential of the wound is better when a more proximal surgery is performed, as proximal perfusion is more likely to be sufficient in these patients or can be improved through percutaneous transluminal angioplasty (PTA) or open vascular surgery [13]. Patients with PAD also usually have numerous comorbidities and risk factors [14], which can influence strategy and level of amputation. If a vascular patient requires amputation surgery due to ischemia of the limb, coronary arterial disease (CAD) should be considered in addition to PAD, and cardiac function should be evaluated $[1,2$, 15]. The presence of CAD in addition to PAD is a primary consideration when determining a safe level for performing an amputation with a good healing potential and to avoid major revision surgery $[16,17]$.

On the other hand, preservation of a major joint leads to a higher probability of ambulation and less energy expenditure [3, 18-21]. Since most vascular patients have severe cardiac and pulmonary limitations as well, a below-knee amputation provides a better likelihood for the patient to resume ambulation. 
Given the above considerations, it is understandable why a below-knee amputation would be preferred, if there is a reasonable chance of success. Determining the level of amputation for a patient depends largely on clinical vascular measurements, through both non-invasive and invasive techniques. Simple clinical investigations such as determining capillary refill or taking the pulses of the dorsal pedal and posterior tibial artery may give a first impression of wound healing potential. With structured training, duplex ultrasound is a low cost, reproducible, effective diagnostic tool for detection of PAD [22]. If a diagnosis of PAD has been made, revascularization strategies can be determined based on the location and morphology of the pathology. Ankle brachial index (ABI) and transcutaneous oxygen pressure (TcPO2) are measurements that can predict wound healing potential $[23,24]$. In a study by Poredos et al [24], TcPO2 levels $>40 \mathrm{mmHg}$ predicted primary wound healing in $100 \%$ of patients, while TcPO2 levels $\leq 10 \mathrm{mmHg}$ predicted $0 \%$ primary wound healing. For intermediate TcPO2 levels, primary healing rates ranged from $54 \%$ for $10-20 \mathrm{mmHg}$, to $70 \%$ for $20-30 \mathrm{mmHg}$, and $88 \%$ for $30-40 \mathrm{mmHg}$.

The purpose of this study was to determine predictive factors for revision of major lower extremity amputations in patients with $\mathrm{PAD}$ and to investigate the effect of preoperative $\mathrm{TcPO} 2$ levels on amputation level and the need for revision.

\section{Patients and methods}

\section{Study design}

We conducted a retrospective chart review of prospectively collected data of all major lower extremity amputations performed at our institution between 2002 and 2016. Our institution specializes in the treatment of patients with diabetes and patients with $\mathrm{PAD}$, poor vascular status or ischemia. The search keyword for the in-house database was "amputation". Exclusion criteria were amputations due to trauma or tumor within $20 \mathrm{~cm}$ of the amputation level, primary amputations performed at another institution, and minor amputations (i.e., at or below the level of the ankle) [25], which were all manually subtracted from the primary search result. This study was reviewed and approved by the local research ethics committee, and informed consent was obtained according to the committee's regulations.

Patient demographics and clinical data were derived from the institutional electronic medical records. All data were collected prospectively. In all cases, amputation level was determined by a senior orthopedic surgeon, based on angiologic evaluation, the presence of palpable pedal pulses, TcPO2 values if palpable pedal pulses were absent, sufficient mechanically resilient skin on the lower limb, and the exclusion of alternative treatment options. All amputations were performed by or under the direct supervision of an attending orthopedic surgeon. For TcPO2 measurement, the room-temperature probe was applied at the planned site of amputation, 12 to $15 \mathrm{~cm}$ below the knee joint line for below-knee amputations, while the patient was lying flat. Information collected included patient demographic data, level and type of amputation, whether the revision was performed at the same level or a more proximal level, time from amputation to first revision, and presence of polyneuropathy or diabetic nephropathy. For diabetes mellitus, the date of diagnosis, type (1 or 2 ), duration, and treatment (none, insulin, oral antidiabetic medications) were determined from the medical records. Peripheral arterial disease was graded using Fontaine stages I to IV [26], and it was noted whether ipsilateral PTA or peripheral bypasses were performed prior to amputation. Risk factors including smoking and alcohol use [27] were extracted.

\section{Statistical analysis}

Data were analyzed using IBM SPSS Statistics version 20.0 (IBM Corp, Armonk, New York). Differences in categorical variables between patients who underwent revision and those without revision were analyzed using chi-square tests. Differences in continuous variables were analyzed using logistic regression. Differences in PAD stage between patients who underwent revisions at the same level or level above were analyzed using Fisher's exact test. The level of statistical significance was set at $\alpha=0.05$.

\section{Results}

\section{Patient demographics and comorbidities}

A total of 182 patients with PAD who underwent major lower extremity amputation between 2002 and 2016 were identified. Two patients were excluded due to missing follow-up data. Of the remaining 180 patients, 125 (69\%) were males, with a mean age at first amputation of 65.7 years (range: 32 to 90) (Table I). The 55 females had a mean age of 68.6 years (range: 31 to 93). Mean followup was 814 (range: 3 to 4,229 ) days. 34 patients (18.9\%) died during the study period, at a mean of 766 (range: 3 to 3,512 ) days after the first amputation. The cause of death was related to the underlying severe infection in four patients; the cause of death was not listed in the charts for the remaining 30 patients.

Almost one-half of patients $(83 / 180,46.1 \%)$ had PAD at Fontaine stage IV (Table I). Patients in the early stages of PAD (I and IIa) who required amputation had severe soft tissue infection or osteomyelitis $(n=20)$, a combination of infection and ischemia $(n=5)$, or new onset of gangrene $(\mathrm{n}=4)$.

A diagnosis of CAD was recorded for 71 patients (39.4\%), and 93 patients $(51.7 \%)$ had undergone a previous balloon angioplasty. A diagnosis of diabetes mellitus was recorded for 104 (57.8\%) patients: 22/104 (21.2\%) had type I diabetes and 82/104 (78.9\%) had type 2 diabetes. Most of the diabetic patients $(70.1 \%)$ were taking insulin injections. 
Table I. Demographics of patients who underwent major lower extremity amputation $(n=180)$ and amputation patients who required revision surgery $(n=54)$.

\begin{tabular}{|c|c|c|c|c|}
\hline & $\begin{array}{c}\text { All amputation } \\
\text { patients }(n=180)\end{array}$ & $\begin{array}{c}\text { Revision } \\
\text { patients }(n=54)\end{array}$ & $\begin{array}{l}\text { No revision } \\
(n=126)\end{array}$ & P-value \\
\hline Gender: male & $125(69.4 \%)$ & $41(75.9 \%)$ & $84(66.7 \%)$ & $0.289^{1}$ \\
\hline Age, years; mean (range) & $66.48(31-93)$ & $65.58(35-84)$ & $68.93(31-92)$ & $0.388^{2}$ \\
\hline Bilateral amputation & $25(13.9 \%)$ & $11(20.4 \%)$ & $14(11.1 \%)$ & $0.106^{\wedge}$ \\
\hline Level of amputation or revision: & & & & $0.356^{\wedge}$ \\
\hline Below knee (i.e., transtibial) & $154(85.6 \%)$ & $44(81.5 \%)$ & $110(87.3 \%)$ & \\
\hline Above knee (i.e., transfemoral) & $26(14.4 \%)$ & $10(18.5 \%)$ & $16(12.7 \%)$ & \\
\hline Reason for amputation: & & & & $0.201^{\wedge}$ \\
\hline Infection & $50(27.8 \%)$ & $11(20.4 \%)$ & $39(30.9 \%)$ & \\
\hline Gangrene & $43(23.9 \%)$ & $12(22.2 \%)$ & $31(24.6 \%)$ & \\
\hline Acute ischemia & $33(18.3 \%)$ & $15(27.8 \%)$ & $18(14.3 \%)$ & \\
\hline Gangrene and infection & $27(15 \%)$ & $9(16.7 \%)$ & $18(14.3 \%)$ & \\
\hline Osteomyelitis & $10(5.6 \%)$ & $2(3.7 \%)$ & $8(6.3 \%)$ & \\
\hline Ischemia and infection & $4(2.2 \%)$ & $2(3.7 \%)$ & $2(1.6 \%)$ & \\
\hline Recurrent foot ulcer & $4(2.2 \%)$ & $1(1.8 \%)$ & $3(2.4 \%)$ & \\
\hline Other ${ }^{1}$ & $9(5 \%)$ & $2(3.7 \%)$ & $7(5.6 \%)$ & \\
\hline PAD stage ${ }^{2}$ & & & & $0.231^{\wedge}$ \\
\hline No stage assigned & $44(24.4 \%)$ & $11(20.4 \%)$ & $33(26.2 \%)$ & \\
\hline Stage I & $17(9.4 \%)$ & $4(7.4 \%)$ & $13(10.3 \%)$ & \\
\hline Stage Ila & $12(6.7 \%)$ & 0 & $12(9.5 \%)$ & \\
\hline Stage IIb & $17(9.5 \%)$ & $5(9.3 \%)$ & $12(9.5 \%)$ & \\
\hline Stage III & $7(3.9 \%)$ & $3(5.6 \%)$ & $4(3.2 \%)$ & \\
\hline Stage IV & $83(46.1 \%)$ & $31(57.4 \%)$ & $52(41.3 \%)$ & \\
\hline Coronary arterial disease & $71(39.4 \%)$ & $25(46.3 \%)$ & $46(36.5 \%)$ & $0.246^{\wedge}$ \\
\hline Diabetes mellitus & $104(57.8 \%)$ & $36(66.7 \%)$ & $68(54.0 \%)$ & $0.139^{\wedge}$ \\
\hline Previous balloon angioplasty & $93(51.7 \%)$ & $36(66.7 \%)$ & $57(45.2 \%)$ & $0.009^{\wedge}$ \\
\hline ТсPO2 & $(n=67)$ & $(n=24)$ & $(n=43)$ & $0.382^{\circ}$ \\
\hline$\geq 40 \mathrm{mmHg}$ & 40/67 (59.7\%) & $16 / 24(66.7 \%)$ & $24 / 43(55.8 \%)$ & \\
\hline$\geq 30$ to $<40 \mathrm{mmHg}$ & 16/67 (23.9\%) & $5 / 24(20.8 \%)$ & $11 / 43(25.6 \%)$ & \\
\hline$\geq 20$ to $<30 \mathrm{mmHg}$ & $3 / 67(4.5 \%)$ & $1 / 24(4.2 \%)$ & $2 / 43(4.7 \%)$ & \\
\hline$\geq 10$ to $<20 \mathrm{mmHg}$ & 4/67 (6\%) & $2 / 24(8.4 \%)$ & $2 / 43(4.7 \%)$ & \\
\hline$<10 \mathrm{mmHg}$ & $4 / 67(6 \%)$ & 0 & $4 / 43(9.3 \%)$ & \\
\hline Smoking & $(n=158)$ & $(n=50)$ & $(n=108)$ & $0.465^{\wedge}$ \\
\hline Never & $61 / 158(38.6 \%)$ & $20 / 50(40.0 \%)$ & 41/108 (38.0\%) & \\
\hline Yes - currently & $46 / 158(25.3 \%)$ & $17 / 50(34.0 \%)$ & 29/108 (26.9\%) & \\
\hline Former Smoker (date of discontinuation not available) & $51 / 158(32.3 \%)$ & $13 / 50(26.0 \%)$ & $38 / 108(35.2 \%)$ & \\
\hline Alcohol consumption: yes & $83 / 170(48.8 \%)$ & $27 / 51(52.9 \%)$ & $56 / 119(47.1 \%)$ & $0.486^{\wedge}$ \\
\hline$<1$ glass of beer or wine/day & $51 / 170(30.0 \%)$ & $14 / 51(25.9 \%)$ & $37 / 119(31.1 \%)$ & \\
\hline 1 glass of beer or wine/day & $13 / 170(7.6 \%)$ & $6 / 51(11.8 \%)$ & $7 / 119(5.9 \%)$ & \\
\hline$>1$ glass of beer or wine/day & $19 / 170(11.2 \%)$ & $7 / 51(13.7 \%)$ & $12 / 119(10.1 \%)$ & \\
\hline
\end{tabular}

${ }^{1}$ Other reasons include: tumor at the level of the foot $(n=3)$, Charcot neuroarthropathy $(n=2)$, delayed nonunion after ankle fusion ( $\left.n=2\right)$, complex regional pain syndrome $(n=1)$; insufficient bone stock for a fifth revision of total knee arthroplasty $(n=1)$.

${ }^{2}$ PAD: peripheral arterial occlusive disease. Stages according to Fontaine et al (1954) (26); in 44 patients, no PAD stage was assigned; ${ }^{\wedge}$ Chi-square analysis;

${ }^{+}$T-test; ${ }^{\circ}$ Logistic regression.

The most common reasons for amputation were infection $(27.8 \%)$, gangrene (23.9\%), acute ischemia (18.3\%), and combined gangrene and infection (15.0\%) Most patients $(154 / 180,86.6 \%)$ underwent below-knee amputation as the index operation (Table I). 25 patients underwent bilateral amputations.

Patients with PAD who required revision of the amputation were similar to patients with PAD who did not undergo revision for gender, age, level of amputation, reason for amputation, $\mathrm{PAD}$ stage, $\mathrm{CAD}$, diabetes, smoking status and alcohol consumption (Table I). Although more patients who required amputation due to acute ischemia subsequently underwent revision (27.8\% versus $14.3 \%)$ and fewer patients who required amputation due to infection subsequently underwent revision (20.4\% versus $30.9 \%$ ), these differences were not statistically significant $(\mathrm{p}=0.201)$. Significantly more patients with PAD who required revision of the amputation had undergone a 
previous PTA compared to patients who did not require revision $(66.7 \%$ versus $45.2 \%, \mathrm{p}=0.009)$.

\section{Revision surgery}

54 (30\%) patients required revision surgery; $42 / 54$ (77.7\%) underwent revision at the same level, and 12/54 (22.2\%) required revision to a more proximal level (11 to transfemoral, 1 to through the knee). The mean time from amputation to first revision was 92.7 (range: 5 to 642) days. 10 of 54 patients $(18.5 \%)$ underwent more than one revision surgery. Three patients underwent two revisions: one patient was converted from transtibial to transfemoral level after 145 days due to skin necrosis and ischemia; two patients were revised at the same level. Seven patients underwent three or more revisions: four with soft tissue infection, two with delayed wound healing, and one with a planned second and third investigation after undergoing amputation due to necrotizing fasciitis; none of these patients were converted to a more proximal level.

The PAD stage was known for 43 of 54 (79.6\%) patients who required revision surgery (Table II). Seven of $11(63.6 \%)$ patients with stage I, II, or III PAD and 24 of $31(77.4 \%)$ patients with stage IV PAD underwent revision at the same level $(\mathrm{p}=0.4369)$. One patient who underwent two revisions, first at the same level and subsequently at a more proximal level, was excluded from this analysis. TcPO2 levels $67(37.2 \%)$ of 180 patients in this retrospective study underwent preoperative $\mathrm{TcPO} 2$ measurement. Of these, 40 patients $(59.7 \%)$ had a preoperative $\mathrm{TcPO} 2 \geq 40 \mathrm{mmHg}$ Table I), which is considered the limit above which wound healing can be expected. Interestingly, the four patients with $\mathrm{TcPO} 2<10 \mathrm{mmHg}$ did not require revision.

In the 67 patients with preoperative TcPO2 measurements available, 64 (95.5\%) underwent below-knee amputation and $3(4.5 \%)$ underwent above-knee amputation (Table III). Twenty-three (35.9\%) below-knee amputations required revision, and $1(33.3 \%)$ above-knee amputation required revision.

The overall revision rate was $35.8 \%$ for patients with a preoperative TcPO2 measurement compared to $26.5 \%$ for patients who had no preoperative TcPO2 measurements ( $p=0.239$, Fisher's exact test). A single revision was performed in $29.9 \%$ of patients with preoperative TcPO2 measurements available and $20.4 \%$ of patients without TcPO2 measurements $(\mathrm{p}=0.239)$. Wound revisions were performed in $28.4 \%$ of patients with preoperative TcPO2 measurements available and in $16.8 \%$ of patients without preoperative TcPO2 measurements $(\mathrm{p}=0.088)$.

TcPO2 measurements were available for 24 patients who required revision surgery. Of these, 16 (66.7\%) patients had TcPO2 levels $\geq 40 \mathrm{mmHg}, 5$ (20.8\%) patients had TcPO2 levels between 30 and $40 \mathrm{mmHg}, 1$ (4.2\%) patient had TcPO2 levels between 20 and $30 \mathrm{mmHg}$, and 2 (8.3\%) patients had TcPO2 levels between 10 and $20 \mathrm{mmHg} .19$ (79.2\%) of 24 patients underwent revision at the same level, whereas 5 (20.8\%) were revised to the level above (Table III).
Table II. PAD stage and level of revision for patients who underwent reoperation (revision) of lower limb amputation.

\begin{tabular}{lc}
\hline PAD stage & $\begin{array}{c}\text { Level of revision* } \\
\text { Same level }(n=31)\end{array}$ \\
\hline Stage I, II, or III $(n=11)$ & $7(63.6 \%)$ \\
Stage IV $(n=31)$ & $24(77.4 \%)$ \\
\hline
\end{tabular}

* One patient underwent 2 revisions, one at the same level and subsequently one at a more proximal level, and was excluded from the table.

\section{Discussion}

Determining the level of amputation in the lower limb is a challenge to the treating surgeon. Several elements, such as comorbidities, capability of assimilating additional energy expenditure, and simplicity of seating position, must be considered. In patients with PAD, poor vascular status or ischemia, wound healing potential has a crucial influence on the choice of amputation level. In our study population of 180 patients with PAD who underwent lower limb amputation, 30\% required revision surgery, with $6.7 \%$ subsequently converted to a more proximal level. Many of these patients also had insulin-dependent diabetes mellitus or CAD.

While many studies have evaluated risk factors for primary lower limb amputation in patients with PAD or critical limb ischemia, the literature on risk factors for revision surgery following primary lower limb amputation is sparse. Wu et al. [28] reported that end-stage renal failure and preoperative non-ambulatory status were independent risk factors for subsequent above-knee amputation in 210 Asian patients with PAD who underwent below-knee amputation. In our study, the only patient factor associated with revision surgery was having undergone a previous PTA ( $p=0.009$ ]. Balloon angioplasty is often considered a surrogate indicator of more severe peripheral vascular disease. As such, PTA is typically only performed in clinically critical patients where the surgeon has concerns about the extent of vascular dysfunction, to aid in decision making regarding the level of amputation, and to potentially improve wound healing following amputation as part of the limb salvage procedure.

The overall revision rate of $30 \%$ in our study population is lower than the $56 \%$ rate observed by Inderbitzi et al in 66 consecutive patients with PAD who underwent bilateral lower limb amputation [1]. While our rate was higher than the mean revision rate of $16.3 \%$ observed in 3,454 lower limb amputations across 12 studies [1-12], some of these studies were not limited to patients with PAD and instead consisted of patient populations with no or varied comorbidities [7, 9-11]. In our study, $6.7 \%$ of patients who underwent amputation required conversion of their amputation to a more proximal level, which is lower than the mean rate of below-knee conversion to a higher level of amputation of $12.9 \%$ (range: $0 \%$ to $24 \%$ ) observed in the other studies [1-12].

Poredos et al. [24] reported that TcPO2 levels $>40 \mathrm{mmHg}$ predicted primary wound healing in $100 \%$ 
Table III. TCPO2 levels in patients undergoing major lower extremity amputation $(n=67)$.

\begin{tabular}{lcccc}
\hline TcPO2 level & $\mathrm{N}$ & $\begin{array}{c}\text { Below-knee } \\
\text { amputation } \\
\text { (i.e., transtibial) }\end{array}$ & & $\begin{array}{c}\text { Above-knee } \\
\text { amputation } \\
\text { (i.e., transfemoral) }\end{array}$ \\
\cline { 3 - 4 }$\geq 40 \mathrm{mmHg}$ & 40 & 39 & 16 & Total \\
$\geq 30$ to $<40 \mathrm{mmHg}$ & 16 & 14 & 4 & 1 \\
$\geq 20$ to $<30 \mathrm{mmHg}$ & 3 & 3 & 1 & 2 \\
$\geq 10$ to $<20 \mathrm{mmHg}$ & 4 & 4 & 2 & 0 \\
$<10 \mathrm{mmHg}$ & 4 & 4 & 0 & 0 \\
\hline
\end{tabular}

of patients in a series of 56 patients who underwent belowknee amputation for ischaemic limb gangrene, whereas TcPO2 levels $\leq 10 \mathrm{mmHG}$ predicted $0 \%$ primary wound healing. In our study, three patients with TcPO2 levels $>40 \mathrm{mmHg}$ before the index amputation required reamputation at a more proximal level. In each of those cases, the indication for reamputation was progressive skin necrosis and declining arterial blood supply, as judged by the treating angiologist. Only two patients with a TcPO2level $<40 \mathrm{mmHg}$ required revision at a higher level in our study. These findings would suggest that determination of TcPO2 levels at the proximal third of the tibia does not safely predict wound healing potential in patients with PAD.

In partial foot amputations, $\mathrm{TcPO} 2$ levels were found to be predictive of wound healing potential [24, 29], which indicates its value in decision-making around amputation level when treating patients with diabetes and/or patients with PAD, poor vascular status or ischemia. While the predictive value of $\mathrm{TcPO} 2$ levels in our study was not demonstrated, perhaps in part due to the limited number of patients for whom this information was available, we believe that the preoperative measurement of the TcPO2 is still a useful tool to provide objective values for discussion of amputation level with the patient.

Many patients with PAD and/or diabetes have significant comorbidities, particularly coronary heart disease, which limits the physical effort they can undertake following lower limb amputation. A below-knee amputation was undertaken in some patients with low preoperative TcPO2 values to preserve lower limb length and minimize the physical effort required for ambulation. In most of these cases, only minor revisions for wound healing problems were observed. Only one patient required revision at a higher level.

\section{Limitations}

Limitations of this study include the retrospective study design, which limited the patient demographic data available for review and may have introduced unintentional bias. Another limitation is the availability of preoperative
TcPO2 levels for only a subset of patients in our study who underwent lower limb amputation. TcPO2 is not routinely performed in all patients who are scheduled for amputation at our institution. The results of this and other studies indicate that a prospective study of preoperative TcPO2 measurement of all patients undergoing lower limb amputation is needed to further elucidate its predictive value for reoperation following primary amputation.

\section{Conclusions}

In conclusion, PAD stage is not predictive of a need for revision surgery following lower limb amputation. TcPO2 measurements are a useful adjunct tool to determine the level of lower limb amputation and to predict wound healing problems in cases where an amputation level with TcPO2 values below $40 \mathrm{mmHg}$ is chosen. However, in transtibial amputations, values above $40 \mathrm{mmHg}$ do not safely predict wound healing, and both the patient and the treating surgeon should be prepared for reamputation at a more proximal level.

\section{References}

1. Inderbitzi, R, Buettiker, M, Enzler, M. The long-term mobility and mortality of patients with peripheral arterial disease following bilateral amputation. Eur J Vasc Endovasc Surg. 2003:26(1):59-64.

2. Nehler, MR, Coll, JR, Hiatt, WR, Regensteiner, JG, Schnickel, GT, Klenke, WA, et al. Functional outcome in a contemporary series of major lower extremity amputations. J Vasc Surg. 2003;38(1):7-14.

3. Pinzur, MS, Gottschalk, F, Smith, D, Shanfield, S, de Andrade, $\mathrm{R}$, Osterman, $\mathrm{H}$, et al. Functional outcome of below-knee amputation in peripheral vascular insufficiency. A multicenter review. Clin Orthop Relat Res. 1993;286:247-9.

4. Mooney, V, Wagner, W Jr, Waddell, J, Ackerson, T. The below-the-knee amputation for vascular disease. J Bone Joint Surg Am. 1976;58(3):365-8.

5. Burgess, EM, Matsen, FA 3rd, Wyss, CR, Simmons, CW. Segmental transcutaneous measurements of $\mathrm{PO} 2$ in patients requiring below-the-knee amputation for peripheral vascular insufficiency. J Bone Joint Surg Am. 1982;64(3):378-82.

6. Fearon, J, Campbell, DR, Hoar, CS Jr, Gibbons, GW, Rowbotham, JL, Wheelock, FC Jr. Improved results with diabetic below-knee amputations. Arch Surg. 1985;120(7):77780.

7. Keagy, BA, Schwartz, JA, Kotb, M, Burnham, SJ, Johnson, G Jr. Lower extremity amputation: the control series. J Vasc Surg. 1986;4(4):321-6.

8. McWhinnie, DL, Gordon, AC, Collin, J, Gray, DW, Morrison, JD. Rehabilitation outcome 5 years after 100 lower-limb amputations. Br J Surg. 1994;81(11):1596-9.

9. Aulivola, B, Hile, CN, Hamdan, AD, Sheahan, MG, Veraldi, JR, Skillman, JJ, et al. Major lower extremity amputation: outcome of a modern series. Arch Surg. 2004;139(4):395-9; discussion 9

10. Brown, BJ, Iorio, ML, Klement, M, Conti Mica, MR, ElAmraoui, A, O'Halloran, P, et al. Outcomes after 294 transtibial amputations with the posterior myocutaneous flap. Int J Low Extrem Wounds. 2014;13(1):33-40.

11. Kristensen, MT, Holm, G, Gebuhr, P. Difficult to predict early failure after major lower-extremity amputations. Dan Med J. 2015;62(12):A5172. 
12. Columbo, JA, Nolan, BW, Stucke, RS, Rzucidlo, EM, Walker, $\mathrm{KL}$, Powell, RJ, et al. Below-Knee Amputation Failure and Poor Functional Outcomes Are Higher Than Predicted in Contemporary Practice. Vasc Endovascular Surg. 2016;50(8):554-8.

13. Schreuder, SM, Hendrix, Y, Reekers, JA, Bipat, S. Predictive Parameters for Clinical Outcome in Patients with Critical Limb Ischemia Who Underwent Percutaneous Transluminal Angioplasty (PTA): A Systematic Review. Cardiovasc Intervent Radiol. 2018;41(1):1-20.

14. Ziegler-Graham, K, MacKenzie, EJ, Ephraim, PL, Travison, TG, Brookmeyer, R. Estimating the prevalence of limb loss in the United States: 2005 to 2050. Arch Phys Med Rehabil. 2008; 89(3):422-9.

15. Robbins, JM, Strauss, G, Aron, D, Long, J, Kuba, J, Kaplan, $Y$. Mortality rates and diabetic foot ulcers: is it time to communicate mortality risk to patients with diabetic foot ulceration? J Am Podiatr Med Assoc. 2008;98(6):489-93.

16. Pinzur, MS. Amputation level selection in the diabetic foot. Clin Orthop Relat Res. 1993;296:68-70.

17. Pinzur, MS, Sage, R, Stuck, R, Osterman, H. Amputations in the diabetic foot and ankle. Clin Orthop Relat Res. 1993;296: $64-7$.

18. Pinzur, MS. Gait analysis in peripheral vascular insufficiency through-knee amputation. J Rehabil Res Dev. 1993;30(4): 388-92.

19. Pinzur, MS, Smith, D, Tornow, D, Meade, K, Patwardhan, A. Gait analysis of dysvascular below-knee and contralateral through-knee bilateral amputees: a preliminary report. Orthopedics. 1993;16(8):875-9.

20. Gjovaag, T, Mirtaheri, P, Starholm, IM. Carbohydrate and fat oxidation in persons with lower limb amputation during walking with different speeds. Prosthet Orthot Int. 2017: 309364617740237

21. Jarvis, HL, Bennett, AN, Twiste, M, Phillip, RD, Etherington, J, Baker, R. Temporal Spatial and Metabolic Measures of Walking in Highly Functional Individuals With Lower Limb Amputations. Arch Phys Med Rehabil. 2017;98(7):1389-99.

22. Zygmunt, JA. Duplex ultrasound for chronic venous insufficiency. J Invas Cardiol. 2014;26(11):E149-55.

23. Crawford, F, Welch, K, Andras, A, Chappell, FM. Ankle brachial index for the diagnosis of lower limb peripheral arterial disease. Cochrane Database Syst Rev. 2016;9: CD010680.

24. Poredos, P, Rakovec, S, Guzic-Salobir, B. Determination of amputation level in ischaemic limbs using tcPO2 measurement. Vasa. 2005;34(2):108-12.
25. Larsson, J, Apelqvist, J, Agardh, CD, Stenstrom, A. Decreasing incidence of major amputation in diabetic patients: a consequence of a multidisciplinary foot care team approach? Diabet Med. 1995;12(9):770-6.

26. Fontaine, R, Kim, M, Kieny, R. Surgical treatment of peripheral circulation disorders. Helv Chir Acta. 1954;21(56):499-533

27. Bell, S, Daskalopoulou, M, Rapsomaniki, E, George, J, Britton, A, Bobak, M, et al. Association between clinically recorded alcohol consumption and initial presentation of 12 cardiovascular diseases: population based cohort study using linked health records. BMJ (Clinical research ed). 2017;356: j909.

28. Wu, JT, Wong, M, Lo, ZJ, Wong, WE, Narayanan, S, Tan, GWL, et al. A Series of 210 Peripheral Arterial Disease BelowKnee Amputations and Predictors for Subsequent AboveKnee Amputations. Ann Vasc Dis. 2017;10(3).

29. Andrews, KL, Dib, MY, Shives, TC, Hoskin, TL, Liedl, DA, Boon, AJ. Noninvasive arterial studies including transcutaneous oxygen pressure measurements with the limbs elevated or dependent to predict healing after partial foot amputation. Am J Phys Med Rehabil. 2013;92(5):385-92.

\section{History}

Submitted: 31.01.2019

Accepted after revision: 20.03.2019

Published online: 07.05.2019

\section{Acknowledgement}

The authors thank Dagmar Gross for assistance with preparation of this manuscript.

\section{Conflicts of interests}

No conflicts of interest exist.

\section{Correspondence address}

Martin Berli, MD

Department of Orthopedics

Balgrist University Hospital

University of Zurich

Forchstrasse 340

8008 Zurich

Switzerland

martin.berli@balgrist.ch 